\title{
Hubungan Usia dan Paritas dengan Kejadian Mioma Uteri di RSUD Al-Ihsan Provinsi Jawa Barat Tahun 2017
}

\author{
Neneng Sri Meilani, ${ }^{1}$ Ferry A Firdaus Mansoer, ${ }^{2}$ Ismet M Nur, ${ }^{3}$ Dadi S Argadireja, ${ }^{4}$ \\ Hidayat Widjajanegara ${ }^{5}$ \\ ${ }^{1}$ Program Studi Pendidikan Dokter, ${ }^{2,5}$ Departemen Obstetri dan Ginekologi, ${ }^{3}$ Departemen Patologi Anatomi, \\ ${ }^{4}$ Departemen Kesehatan Masyarakat, Fakultas Kedokteran, Universitas Islam Bandung
}

\begin{abstract}
Abstrak
Mioma uteri adalah tumor jinak otot polos rahim yang paling umum terjadi pada wanita. Kejadian mioma uteri di dunia ditemukan sebesar 20-35\% dan di Indonesia mioma uteri ditemukan 2,39-11,7\% pada semua pasien ginekologi yang dirawat di RSUD Al-Ihsan Bandung Jawa Barat periode Mei-Juni 2018. Penelitian bertujuan mengetahui hubungan usia dan paritas dengan kejadian mioma uteri. Penelitian ini menggunakan metode observasi analitik dengan pendekatan cross sectional. Sampel dalam penelitian ini didapatkan 84 sampel yang terdiri atas 42 sampel yang didiagnosis mioma uteri dan 42 sampel yang tidak didiagnosis mioma uteri. Data didapatkan dari catatan rekam medik pasien yang dirawat periode tahun 2017 yang kemudian dianalisis secara uivariat dan bivariat. Dari hasil penelitian insidensi mioma uteri, paling banyak terjadi pada paritas nulipara, yaitu sebanyak $62 \%$ dan pada usia lebih dari 30 tahun $56 \%$. Hasil uji statistik menggunakan chi square test didapatkan bahwa terdapat hubungan bermakna antara usia dan kejadian mioma uteri $(\mathrm{p}=0,0150)$ dan status paritas dengan kejadian mioma uteri $(\mathrm{p}=0$,035). Simpulan penelitian ini membuktikan bahwa terdapat hubungan usia dan paritas dengan kejadian mioma uteri.
\end{abstract}

Kata kunci: Mioma uteri, paritas, usia

\section{The Relationship of Age and Parity with Incidence of Uterine Myoma in RSUD Al-Ihsan Province West Java Year 2017}

\begin{abstract}
Uterine myoma is a benign smooth muscle tumor of the uterus which most often occurs in women. The incidence of uterine myoma in the world was found $20-35 \%$ and in Indonesia uterine myoma was found $2.39-11.7 \%$ in all gynecological patients treated. This study aims to determine the relationship between age and parity with the incidence of uterine myoma in RSUD Al-Ihsan Province West Java during May-June 2017. This research used analytical observation method with cross sectional approach design. The sample in this study obtained 84 samples consisting of 42 samples diagnosed with uterine myoma and 42 samples that were not diagnosed with uterine myoma. Data were obtained from patient's medical records, then analyzed by uivariate and bivariate analysis. From the results of the study about uterine myoma incidence, that the most occur in nullipara parity as many as $62 \%$ and at the age of more than 30 years $56 \%$. The results of statistical tests used chi square test showed that there was a significant relationship between age and the incidence of uterine myoma $(\mathrm{p}=0.015)$ and for parity status with the incidence of uterine myoma also had a significant relationship $(\mathrm{p}=0.0350)$. Conclusion, this study proves that there is a relationship between age and parity with the incidence of uterine myoma.
\end{abstract}

Keywords: Age, parity, uterine myoma

Korespondensi: Neneng Sri Meilani. Program Studi Pendidikan Dokter, Fakultas Kedokteran, Universitas Islam Bandung, Jalan Tamansari No.22,40116, Kota Bandung, Provinsi Jawa Barat, Hp: 085222221194 Email nsrimeilani@yahoo.com 


\section{Pendahuluan}

Mioma uteri adalah neoplasma jinak otot polos yang berasal dari otot uterus, dalam kepustakaan dikenal juga istilah fibromioma, leomioma, ataupun fibroid. ${ }^{1}$ Mioma uteri adalah tumor jinak otot polos rahim yang paling umum terjadi pada wanita. Diperkirakan insidens mioma uteri sekitar $20-25 \%$ terjadi pada wanita reproduktif. Kejadian mioma uteri di dunia ditemukan sebesar $20-35 \%$ dan di Indonesia mioma uteri ditemukan $2,39-11,7 \%$ pada semua penderita ginekologi yang dirawat. ${ }^{2,3}$ Jumlah kejadian penyakit ini di Indonesia menempati urutan kedua setelah kanker serviks. ${ }^{4}$

Mioma uteri memiliki banyak faktor risiko yang meningkat seiring dengan peningkatan usia. Risiko mioma uteri meningkat pada wanita nulipara. Mioma umumnya ditemukan pada wanita usia reproduksi dan belum pernah dilaporkan terjadi sebelum menarche. Pada masa menopause, mioma akan mengecil seiring dengan penurunan hormon estrogen dalam tubuh. ${ }^{5}$ Stimulasi estrogen diduga sangat berperan untuk terjadinya mioma uteri. ${ }^{1}$

Pada penelitian yang telah dilakukan oleh Agustian dkk. ${ }^{6}$ di RSUP Dr. Mohammad Hoesin Palembang, tumor ini paling banyak ditemukan pada wanita dengan kelompok usia 35-45 tahun sebesar $72 \%$ dan paling sedikit pada kelompok usia lebih dari $>45$ tahun sebesar $29,20 \%$. Pada wanita multipara kejadiannya lebih rendah, yaitu $33,3 \%$, sedangkan pada nulipara $75,7 \%$. Hal ini menunjukkan peningkatan paritas menurunkan insidensi terjadinya mioma uteri. Berdasar atas usia kejadian mioma uteri lebih sering terjadi pada usia reproduktif. ${ }^{6}$

Tujuan penelitian ini adalah mengetahui hubungan usia dan paritas dengan kejadian mioma uteri di RSUD AL-Ihsan Provinsi Jawa Barat.

\section{Metode}

Metode penelitian yang digunakan adalah observasi analitik dengan desain studi potong lintang (cross sectional). Data yang diperoleh pada penelitian ini menggunakan data sekunder berupa rekam medik. Penelitian dilakukan di RSUD Al-Ihsan Provinsi Jawa Barat pada bulan Mei 2018 hingga bulan Juni 2018.

Sampel pada penelitian ini adalah pasien wanita yang didiagnosis mioma uteri dan tercatat di rekam medik RSUD Al-Ihsan Provinsi Jawa Barat periode tahun 2017. Teknik pengambilan sampel menggunakan total sampling dan didapatkan sampel sebanyak 42 orang. Responden pada penelitian ini harus memenuhi kriteria inklusi dan tidak termasuk eksklusi.

Kriteria inklusi adalah semua wanita yang diagnosis mioma uteri dan tercatat di rekam medik RSUD AlIhsan Provinsi Jawa Barat pada tahun 2017. Kriteria eksklusi adalah wanita yang didiagnosis mioma uteri yang menggunakan alat kontrasepsi dalam rahim (AKDR) atau obat-obatan kontrasepsi, wanita yang memiliki kista pada rahim, dan wanita hamil.

Penelitian ini menggunakan metode analisis univariat yang bertujuan mengetahui distribusi frekuensi tiap-tiap varibel, yaitu variabel bebas dan variabel terikat menggunakan persentase. Analisis dilanjutkan menggunakan analisis bivariat untuk mengetahui hubungan usia dan paritas dengan kejadian mioma uteri. Analisis data dilakukan dengan menggunakan statistical product and service solution (SPSS) versi 23.

Penelitian ini telah mendapatkan surat izin etik dari Komite Etik Penelitian Kesehatan Fakultas Kedokteran Universitas Islam Bandung dengan Nomor: 276/Komite Etik FK/III/2018.

\section{Hasil}

Berikut adalah hasil penelitian mengenai gambaran distribusi kelompok yang mengalami mioma uteri dan kelompok yang tidak mengalami mioma uteri di RSUD Al-Ihsan berdasar atas usia yang dapat dilihat pada Tabel 1.

Tabel 1 Distribusi Frekuensi Usia berdasar atas Kejadian Mioma Uteri di RSUD Al-Ihsan Provinsi Jawa Barat Tahun 2017

\begin{tabular}{lcccc}
\hline & \multicolumn{3}{c}{ Kejadian Mioma Uteri } \\
\cline { 2 - 5 } $\begin{array}{c}\text { Usia } \\
\text { (Tahun) }\end{array}$ & \multicolumn{2}{c}{ Mioma } & \multicolumn{2}{c}{ Non-mioma } \\
\cline { 2 - 5 } & $\mathbf{n = 4 2}$ & $\mathbf{\%}$ & $\mathbf{n = 4 2}$ & $\mathbf{\%}$ \\
\hline $20-25$ & 0 & 0 & 6 & 14 \\
$26-30$ & 2 & 5 & 5 & 12 \\
$>30$ & 40 & 95 & 31 & 74 \\
\hline
\end{tabular}

Tabel 1 di atas menunjukkan bahwa karakteristik responden berdasar atas usia pada kelompok mioma uteri paling banyak terjadi pada usia lebih dari 30 tahun sebanyak 40 responden (95\%).

Kelompok yang tidak mengalami mioma uteri paling banyak pada pada usia lebih dari 30 tahun (74\%).

Tabel 2 Distribusi Frekuensi Paritas berdasar atas Kejadian Mioma Uteri di RSUD Al-Ihsan Provinsi Jawa Barat Tahun 2017

\begin{tabular}{lcccc}
\hline \multirow{4}{*}{ Paritas } & \multicolumn{3}{c}{ Kejadian Mioma Uteri } \\
\cline { 2 - 5 } & \multicolumn{2}{c}{ Mioma } & \multicolumn{2}{c}{ Non-mioma } \\
\cline { 2 - 5 } & $\mathbf{n = 4 2}$ & $\mathbf{\%}$ & $\mathbf{n = 4 2}$ & $\mathbf{\%}$ \\
\hline Nulipara & 26 & 62 & 16 & 38 \\
Primipara & 11 & 26 & 12 & 29 \\
Multipara & 5 & 12 & 14 & 33 \\
\hline
\end{tabular}

Kelompok yang mengalami mioma uteri paling banyak pada kategori nulipara 26 responden (62\%). Kelompok yang tidak mengalami mioma uteri paling banyak pada nulipara sebanyak 16 responden (38\%). (Tabel 2)

Tabel 3 Hubungan Usia dengan Kejadian Mioma Uteri di RSUD Al-Ihsan Provinsi Jawa Barat Tahun 2017

\begin{tabular}{cccccc}
\hline \multirow{2}{*}{$\begin{array}{c}\text { Usia } \\
\text { (Tahun) }\end{array}$} & \multicolumn{3}{c}{ Kejadian Mioma Uteri } & \multirow{2}{*}{ Nilai p } \\
\cline { 2 - 5 } & \multicolumn{2}{c}{ Mioma } & \multicolumn{2}{c}{ Non-mioma } & \\
\cline { 2 - 5 } & $\mathbf{n}=\mathbf{4 2}$ & $\mathbf{\%}$ & $\mathbf{n = 4 2}$ & $\mathbf{\%}$ & \\
\hline $20-25$ & 0 & 0 & 6 & 100 & \\
$26-30$ & 2 & 29 & 5 & 71 & \multirow{2}{*}{0,015} \\
$>30$ & 40 & 56 & 31 & 44 & \\
\hline
\end{tabular}


Berdasar atas Tabel 3 hubungan antara paritas dan kejadian mioma uteri di RSUD Al-Ihsan Provinsi Jawa Barat tahun $2017(\mathrm{p}=0,015)$.

Tabel 4 Hubungan Paritas dengan Kejadian Mioma Uteri di RSUD Al-Ihsan Provinsi Jawa Barat Tahun 2017

\begin{tabular}{lrrrrr}
\hline \multirow{2}{*}{ Paritas } & \multicolumn{3}{c}{ Kejadian Mioma Uteri } & \multirow{2}{*}{ Nilai p } \\
\cline { 2 - 4 } & \multicolumn{2}{c}{ Mioma } & \multicolumn{2}{c}{ Non-Moma } & \\
\cline { 2 - 4 } & $\mathbf{n}$ & \% & n & \% & \\
\hline Nulipara & 26 & 62 & 16 & 38 & \\
Primipara & 11 & 48 & 12 & 52 & \multirow{2}{*}{0,035} \\
Multipara & 5 & 26 & 14 & 74 & \\
\hline
\end{tabular}

Terdapat hubungan bermakna antara paritas dan kejadian mioma uteri di RSUD Al-Ihsan Provinsi Jawa Barat tahun $2017(\mathrm{p}=0,035)$.

\section{Pembahasan}

Berdasar atas Tabel 1 diperlihatkan bahwa dari 42 responden yang mengalami mioma uteri paling banyak terjadi pada usia lebih dari 30 tahun dengan jumlah responden 40 orang (95\%) dan lebih banyak dibanding dengan kelompok usia 26-30 tahun, yaitu sebanyak 2 responden $(5 \%)$ dan usia $20-25$ tahun sebanyak o responden (o\%). Keadaan ini menunjukkan bahwa kelompok usia di atas 30 tahun lebih berisiko terkena mioma uteri.

Hasil penelitian berdasar atas usia, mioma uteri lebih banyak terjadi pada usia lebih dari 30 tahun, hal ini disebabkan oleh pertumbuhan dan perkembangan mioma uteri dipengaruhi oleh stimulsi hormon estrogen yang disekresikan oleh ovarium. ${ }^{7}$ Klatsky dkk. ${ }^{8}$ menyatakan bahwa estrogen sangat berperan terjadi mioma uteri disebabkan oleh kadar estrogen tinggi pada masa usia reproduktif. Pada usia menopause terjadi regresi mioma uteri karena kedua ovarium sudah tidak menghasilkan estrogen lagi. Pada usia sebelum menarche kadar estrogen rendah. ${ }^{8}$

Mioma uteri terjadi pada wanita berusia lebih dari 30 tahun, tetapi dapat juga tumbuh pada wanita usia berapapun. Peningkatan miom pada usia lebih dari 30 tahun terkait dengan stimulasi hormon estrogen yang dihasilkan oleh ovarium yang mengalami peningkatan pada usia reproduksi. Mioma uteri pada umumnya tumbuh tanpa gejala, tetapi dapat juga tumbuh dengan menimbulkan gejala. ${ }^{9}$

Wiknjosastro dkk. ${ }^{10}$ menyatakan bahwa frekuensi kejadian mioma uteri paling tinggi pada usia $35-50$ tahun mendekati angka 40\%, jarang ditemukan pada usia di bawah 20 tahun. Hal ini dikarenakan pada usia sebelum menarche kadar estrogen rendah dan meningkat pada usia reproduksi, kemudian akan turun pada usia menopause.

Mioma uteri paling banyak terjadi pada wanita yang belum pernah melahirkan atau nulipara $62 \%$ dan paling sedikit pada wanita yang pernah melahirkan sebanyak dua kali atau lebih (multipara) 26\%. Hal ini menunjukkan bahwa wanita yang belum pernah melahirkan atau nulipara berisiko terkena penyakit mioma uteri dibanding dengan wanita yang pernah melahirkan. Paritas merupakan salah satu faktor risiko terjadi mioma uteri. Mioma uteri lebih sering didapati pada wanita nulipara atau yang kurang subur. ${ }^{10}$ Dari hasil penelitian ini paritas tertinggi terjadi mioma uteri adalah paritas nulipara, jadi dapat disimpulkan pada penelitian ini responden yang mengalami kejadian mioma uteri kebanyakan wanita yang kurang subur (infertil).

Hasil penelitian ini sama dengan penelitian yang dilakukan oleh Jannah dkk.12 di RSUD dr. M. Soewandhi Surabaya kejadian mioma uteri hampir seluruhnya terjadi pada paritas nulipara (83,3\%). Penelitian yang lain juga menyatakan bahwa wanita nulipara berisiko tinggi menderita mioma uteri daripada wanita multipara.

Hasil penelitian ini sesuai dengan pendapat Parker $^{9}$ yang menyatakan bahwa peningkatan jumlah paritas akan menurunkan risiko mioma uteri. Mioma uteri memiliki karakteristik yang serupa dengan miometrium normal selama kehamilan, termasuk peningkatan produksi matriks ekstraseluler serta peningkatan ekspresi reseptor hormon steroid dan peptida. Miometrium selama postpartum kembali pada keadaan normal baik dalam ukuran dan aliran darah melalui proses apoptosis dan dediferensiasi. Proses remodeling ini berperan dalam involusi mioma yang responsibel.

Multiparitas dapat menurunkan risiko mioma uteri dapat dikaitkan dengan masa menyusui saat wanita yang baru melahirkan dikarenakan menyusui dapat menekan hormon ovarium termasuk estrogen yang memengaruhi perkembangan mioma. Selain itu, hal ini dapat dikaitkan dengan proses remodeling myometrium postpartum. ${ }^{11}$ Proses remodeling ini bertanggung jawab dalam penurunan ukuran mioma uteri. Miometrium akan kembali kepada berat asal, aliran darah, dan ukuran asal melalui proses apoptosis dan diferensiasi. Teori yang lain juga menyatakan pembuluh darah di uterus kembali kepada keadaan atau ukuran asal pada postpartum dan ini menyebabkan mioma uteri kekurangan suplai darah dan nutrisi untuk membesar. ${ }^{12}$

\section{Simpulan}

Berdasar atas data yang diperoleh dari penelitian di RSUD Al-Ihsan maka dapat ditarik simpulan bahwa terdapat hubungan usia dan paritas dengan kejadian mioma uteri.

\section{Ucapan Terima kasih}

Ucapan terima kasih penulis sampaikan kepada Direktur RSUD Al-Ihsan.

\section{Daftar Pustaka}

1. Hoffmann BL, Schorge JO, Schaffer JI, Halvorson LM, Bradshaw KD, Cunningham FG. Williams gynecology. Texas: Mc Graw Hill; 2012.

2. Mohamad Anwar, Ali Baziad, Prajitno Prabowo. Ilmu kandungan. Edisi ke-3. Jakarta: PT Bina Pustaka Sarwono Prawirohardjo; 2011. 
3. Ilma $\mathrm{N}$, Tjahyadi $\mathrm{D}$, Judistiani $\mathrm{TD}$, The relationship of age, parity, and body mass index as risk factors to the incidence of uterine myoma in Dr. Hasan Sadikin General Hospital. Althea Med J. 2015;2(3):409-13.

4. Pertiwi D. Hubungan usia menarche dan paritas dengan kejadian mioma uteri di RSUD Wates Kulonprogo tahun 2007-2010, Ponorogo. Forum Ilmiah Kesehatan (FORIKES). 2012;3(3):1-6.

5. Pratiwi P, Suparman E, Wagey F. Hubungan usia reproduksi dengan kejadian mioma uteri Di RSUP Prof. DR.R.D. Kandou Manado. J e-Clinic. 2013;1(1):26-30.

6. Agustian W, Kurniawan, Azhari A. Hubungan usia dan paritas dengan kejadian mioma uteri di RSUP Dr. Mohammad Hoesin Palembang periode Januari 2011-Januari 2012. Syifa Medika. 2013;4(1):1-8.

7. Victory R, Romano W, Bennett J, Diamond M. Clinical gynecology. Cambridge: UK. Churchill
Livingstone, an imprint of Elsevier Inc; 2006.

8. Klatsky PC, Tran ND, Caughey AB, Fujimoto VY. Fibroids and reproductive outcomes: a systematic literature review from conception to delivery. Am J Obstet Gynecol. 2008;198(4):357-8.

9. Parker WH. Etiology, Symptomatology and diagnosis of uterine myomas. Am Soc Reproductive Med. 2007;87(4):725-36.

10. Wiknjosastro, Abdul Bari Syapifudin, Trijatmo Rachimhadi. Ilmu kandungan. Jakarta: PT Bina Pustaka Sarwono Prawiroharjo; 2010.

11. Hoffmann BL, Schorge JO, Schaffer JI, Halvorson LM, Bradshaw KD, Cunningham FG. Williams gynecology. Texas: Mc Graw Hill; 2012.

12. Jannah M, Armini NKA, Aulia A. Paritas dan IMT (indeks massa tubuh) berhubungan dengan mioma uteri pada wanita usia subur. PMNJ. 2015;3(2):289-94. 